\title{
A Public Health Law Analysis of Shared Use Agreements in Los Angeles County, 2010-2014
}

\author{
Benjamin D. Winig ${ }^{1,2}$ and Tony Kuo $\mathrm{Ku}^{2,3,4,5 *}$ \\ ${ }^{1}$ ChangeLab Solutions \\ ${ }^{2}$ Framework for Shared Use Workgroup \\ ${ }^{3}$ Los Angeles County Department of Public Health, Division of Chronic Disease \\ and Injury Prevention \\ ${ }^{4}$ UCLA Fielding School of Public Health, Department of Epidemiology \\ ${ }^{5}$ UCLA David Geffen School of Medicine, Department of Family Medicine
}

\begin{abstract}
Los Angeles County communities have implemented a variety of shared use arrangements to promote physical activity among residents who live near schools. However, little has been documented or is presently known about the strengths and limitations of these legal arrangements for achieving this goal. This legal analysis addresses a gap in public health practice. A public health law analysis was conducted to review 20 shared used agreements implemented in Los Angeles County during 2010-2014. Some schools and communities have entered into lengthy, detailed contracts; others have opted for simple applications, licenses, and permits; others have used memoranda of understanding. Findings suggest that regardless of the legal mechanism used to document the parties' intentions, including language that describes each party's interest in community health, health equity, and long-term sustainability represents a best practice that should be considered in every shared use agreement.
\end{abstract}

(C) 2017 Californian Journal of Health Promotion. All rights reserved.

Keywords: policy analysis, regional health planning, public health practice, health promotion, physical activity

\section{Introduction}

Although Los Angeles County public schools have a variety of recreational facilitiesgymnasiums, playgrounds, fields, courts, and tracks-where people can play and exercise, real or perceived concerns about liability, staffing, and maintenance have posed challenges to communities interested in utilizing these facilities for physical activity (Basurto-Dávila, Pourshaban, and Jackson 2014; Cox et al. 2011; DeFosset et al. 2016; Spengler, Connaughton, and Maddock 2011). This is particularly relevant in low-income communities and communities of color, as schools may be the only places where safe and affordable space can be offered to the community during non-school hours (Lafleur et al. 2013; Vincent 2014; Zimmerman, Kramer, and Trowbridge 2013).
To gain access to these underutilized spaces, the public health community, as well as some school districts in Los Angeles County, have embraced the concept of "shared use" (BasurtoDávila, Pourshaban, and Jackson 2014; DeFosset et al. 2016; Lafleur et al. 2013; NPLAN, ChangeLab Solutions, and KaBOOM! 2012). Shared use-also called joint use or community use-occurs when government entities, or sometimes private organizations, agree to open or broaden access to their facilities for community use. While shared use can, and often does, occur on an informal basis, formal arrangements can be documented through a "shared use agreement." A shared use agreement is a written contract between two or more partners that sets forth the terms and conditions for the shared use of the space or facility(-ies) in question (ChangeLab Solutions 2009; NPLAN, ChangeLab Solutions, and KaBOOM! 2012). In the public health literature, 
there is a paucity of studies describing how some of these terms and conditions (the key provisions of a contract) have been drafted to support the intent of these joint arrangements.

This brief communication addresses this gap in the literature by presenting the results from a public health law analysis of 20 Los Angeles County shared use agreements that were implemented during 2010-2014. The agreements were selected for analysis based on their design and intent to facilitate the scale and spread of obesity prevention interventions in the community. They were a part of several major initiatives in the region: (a) the Communities Putting Prevention to Work initiative supported by the Centers for Disease Control and Prevention (CDC); (b) the Nutrition Education and Obesity Prevention Project - funded as a part of the Supplemental Nutrition Assistance Program Education Services (SNAP-Ed) program in Los Angeles; and (c) the County of Los Angeles's Joint Use Moving People to Play (JUMPP) Task Force, the mission of which is to promote shared use interventions in local communities.

From a public health law perspective, facilitating ways in which jurisdictions can use legal provisions to strengthen or tailor shared use partnerships represents an important contribution to public health practice - i.e., helping under-resourced communities maximize utilization of existing space for physical activity promotion and advancing health equity.

\section{Public Health Law Analysis}

ChangeLab Solutions analyzed 20 different documents broadly defined as "shared use agreements.” As indicated above, these agreements were selected for this analysis based on the following criteria: (1) their adoption and implementation occurred during 2010-2014; (2) they were a public health intervention funded by or supported in part by one or more of the three major obesity prevention initiatives described for the identified timeframe; and (3) they addressed the open space needs of underserved communities targeted by the three initiatives (i.e., neighborhoods of South Los Angeles, Metro, and eastern areas of the county; these communities had high child and adult obesity rates). All agreements in the review included a school or school district (no. students in each school/district ranged from $\sim 8,000$ to $>650,0$ $00)$ as a signatory. Table 1 describes the characteristics of these 20 agreements.

\section{Table 1.}

Characteristics of the 20 Shared Use Agreements in Los Angeles County, California

\begin{tabular}{|c|c|c|}
\hline Characteristics & $\begin{array}{l}\text { No. of } \\
\text { Agree- } \\
\text { ments }\end{array}$ & $\begin{array}{l}\text { \% of } \\
\text { Total }\end{array}$ \\
\hline \multicolumn{3}{|l|}{ Year Executed } \\
\hline 2009 & 2 & $10 \%$ \\
\hline 2010 & 5 & $25 \%$ \\
\hline 2011 & 8 & $40 \%$ \\
\hline 2012 & 5 & $25 \%$ \\
\hline \multicolumn{3}{|l|}{ Length of Agreement } \\
\hline 1 page & 5 & $25 \%$ \\
\hline 2-5 pages & 4 & $20 \%$ \\
\hline $6-10$ pages & 4 & $20 \%$ \\
\hline$\geq 11$ pages & 7 & $35 \%$ \\
\hline \multicolumn{3}{|l|}{ Type of Agreement } \\
\hline Application & 13 & $65 \%$ \\
\hline MOU & 2 & $10 \%$ \\
\hline License & 2 & $10 \%$ \\
\hline Permit & 2 & $10 \%$ \\
\hline Program Arrangement & 1 & $5 \%$ \\
\hline \multicolumn{3}{|l|}{ Duration } \\
\hline None/Not Specified & 3 & $15 \%$ \\
\hline 1 Month to 1 Year & 6 & $30 \%$ \\
\hline 2 Years & 6 & $30 \%$ \\
\hline 3-5 Years & 2 & $10 \%$ \\
\hline 6-10 Years & 2 & $10 \%$ \\
\hline$\geq 11$ Years & 1 & $5 \%$ \\
\hline \multicolumn{3}{|l|}{ Indicated in the } \\
\hline \multicolumn{3}{|l|}{ Agreement... } \\
\hline Termination clause & 10 & $50 \%$ \\
\hline Dispute resolution & 3 & $15 \%$ \\
\hline Indemnity & 13 & $65 \%$ \\
\hline Insurance & 16 & $80 \%$ \\
\hline
\end{tabular}




\section{Table 2.}

Forty Standard Provisions or Issues Examined for Each of the Agreements Reviewed, Organized by Key Categories

\begin{tabular}{|c|c|c|c|}
\hline BACKGROUND & LEGAL & SUSTAINABILITY & $\begin{array}{l}\text { FACILITY USE/ } \\
\text { IMPLEMENTATION }\end{array}$ \\
\hline Year of Execution & Agreement & Purpose/Goals & Location \\
\hline Length of Agreement & Type & Duration & Program/Services \\
\hline \multirow{11}{*}{ Unilateral/Bilateral/Trilateral } & Term & Option to Renew & \multirow{11}{*}{$\begin{array}{l}\text { Priority of Uses } \\
\text { Use Period } \\
\text { Primary Beneficiaries } \\
\text { Schedule } \\
\text { Participation/Access Fees } \\
\text { Equipment } \\
\text { Access and Security } \\
\text { Custodial Services } \\
\text { Maintenance/Repair } \\
\text { Rules for Use of Property } \\
\text { Parking } \\
\text { Communication Protocol } \\
\text { Staffing Structure }\end{array}$} \\
\hline & Termination & Evaluation & \\
\hline & Clause & Cost Allocation & \\
\hline & Dispute & Future Costs & \\
\hline & Resolution & Oversight Committee & \\
\hline & Indemnity & Technical Assistance & \\
\hline & Insurance & & \\
\hline & Enforceability+ & & \\
\hline & Remedies & OTHER & \\
\hline & $\begin{array}{c}\text { Independent } \\
\text { Contractor }\end{array}$ & Unique School/ & \\
\hline & $\begin{array}{l}\text { Background } \\
\text { Check }\end{array}$ & $\begin{array}{l}\text { Community Benefits } \\
\text { Equity }\end{array}$ & \\
\hline
\end{tabular}

Additional details about the twenty shared used agreements can be found at: http://publichealthlawresearch.org/product/building-evidencecreating-framework-assessing-costs-and-impacts-shared-use-agreements

Findings from the analysis are synthesized in Tables 2 and 3. As shown in Table 2, 40 agreement provisions or issues, organized by 5 key categories, were examined for each agreement. These five categories were: (1) Background; (2) Legal; (3) Sustainability; (4) Use of Facilities/Implementation; and (5) Other. No single agreement from the 20 reviewed addressed all 40 provisions or issues that were examined for each agreement. Table 3 provides a snapshot of the relative strengths and weaknesses of the terms and conditions (provisions) for all 20 agreements. Symbols in this table signify whether a provision or issue is addressed and whether the language used is "strong" or "weak" based on comprehensiveness, clarity, and enforceability. Some provisions, such as "background check" or "independent contractor," do not lend themselves to strong or weak language, and were classified as either "addressed" or "not addressed" (not shown in the tables).

\section{Reflections and Public Health Considerations} Although much has been written promoting shared use as a strategy to increase opportunities for physical activity (Carlton et al. 2016; Eat Smart Move, More North Carolina 2016; Eat Smart, Move More South Carolina 2015; Young et al. 2014), there has been little discussion about what agreement terms and conditions have been included or how best to document shared use partnerships that are formed to address obesity in particular communities. That is, how have prior shared use agreements included or applied certain provisions to help ensure that a partnership addresses or could address community health, health equity, and long-term sustainability? 
Table 3.

Public Health Law Analysis of 20 Shared-Use Agreements in Los Angeles County, California, 2010-2014

\begin{tabular}{|c|c|c|c|c|c|c|c|}
\hline $\begin{array}{l}\text { Agree- } \\
\text { ment } \\
\text { No. }\end{array}$ & $\begin{array}{l}\text { Staffing } \\
\text { Structure }\end{array}$ & $\begin{array}{l}\text { Enforceability } \\
\text { + Explicit } \\
\text { Remedies }\end{array}$ & Evaluation & $\begin{array}{l}\text { Technical } \\
\text { Assistance }\end{array}$ & $\begin{array}{l}\text { Unique } \\
\text { Benefits } \\
\text { to School/ } \\
\text { Community }\end{array}$ & Equity & $\begin{array}{l}\text { No. of Issues } \\
\text { Not Addressed } \\
\text { Out of } 40 \text { issues } \\
\text { examined for } \\
\text { each } \\
\text { Agreement, } n \\
\text { (\%) }\end{array}$ \\
\hline 1 & $\varnothing$ & $\varnothing$ & $\varnothing$ & $\varnothing$ & $\varnothing$ & $\varnothing$ & $22(55 \%)$ \\
\hline 2 & $\uparrow$ & $\varnothing$ & $\sqrt{ }$ & $\varnothing$ & $\sqrt{ }$ & $\varnothing$ & 14 (35\%) \\
\hline 3 & $\varnothing$ & $\varnothing$ & $\varnothing$ & $\varnothing$ & $\varnothing$ & $\varnothing$ & $24(60 \%)$ \\
\hline 4 & $\varnothing$ & $\varnothing$ & $\varnothing$ & $\varnothing$ & $\varnothing$ & $\varnothing$ & 21 (53\%) \\
\hline 5 & $\varnothing$ & $\varnothing$ & $\varnothing$ & $\varnothing$ & $\varnothing$ & $\varnothing$ & 21 (53\%) \\
\hline 6 & $\varnothing$ & $\sqrt{ }$ & $\varnothing$ & $\varnothing$ & $\varnothing$ & $\varnothing$ & 24 (60\%) \\
\hline 7 & $\downarrow$ & $\varnothing$ & $\varnothing$ & $\varnothing$ & $\varnothing$ & $\varnothing$ & 14 (35\%) \\
\hline 8 & $\varnothing$ & $\varnothing$ & $\varnothing$ & $\varnothing$ & $\varnothing$ & $\varnothing$ & 26 (65\%) \\
\hline 9 & $\downarrow$ & $\sqrt{ }$ & $\varnothing$ & $\varnothing$ & $\sqrt{ }$ & $\varnothing$ & 12 (30\%) \\
\hline 10 & $\downarrow$ & $\sqrt{ }$ & $\varnothing$ & $\varnothing$ & $\sqrt{ }$ & $\varnothing$ & 12 (30\%) \\
\hline 11 & $\uparrow$ & $\sqrt{ }$ & $\varnothing$ & $\varnothing$ & $\sqrt{ }$ & $\sqrt{ }$ & 9 (23\%) \\
\hline 12 & $\varnothing$ & $\varnothing$ & $\varnothing$ & $\varnothing$ & $\varnothing$ & $\varnothing$ & $24(60 \%)$ \\
\hline 13 & $\varnothing$ & $\sqrt{ }$ & $\varnothing$ & $\varnothing$ & $\varnothing$ & $\varnothing$ & 17 (42\%) \\
\hline 14 & $\varnothing$ & $\sqrt{ }$ & $\varnothing$ & $\varnothing$ & $\varnothing$ & $\varnothing$ & $16(40 \%)$ \\
\hline 15 & $\varnothing$ & $\varnothing$ & $\varnothing$ & $\varnothing$ & $\sqrt{ }$ & $\varnothing$ & 22 (55\%) \\
\hline 16 & $\varnothing$ & $\sqrt{ }$ & $\varnothing$ & $\varnothing$ & $\varnothing$ & $\varnothing$ & 17 (42\%) \\
\hline 17 & $\varnothing$ & $\varnothing$ & $\varnothing$ & $\sqrt{ }$ & $\varnothing$ & $\varnothing$ & 21 (53\%) \\
\hline 18 & $\downarrow$ & $\sqrt{ }$ & $\varnothing$ & $\varnothing$ & $\varnothing$ & $\varnothing$ & 14 (35\%) \\
\hline 19 & $\varnothing$ & $\varnothing$ & $\varnothing$ & $\varnothing$ & $\varnothing$ & $\varnothing$ & 26 (65\%) \\
\hline 20 & $\varnothing$ & $\varnothing$ & $\varnothing$ & $\varnothing$ & $\varnothing$ & $\varnothing$ & $14(35 \%)$ \\
\hline
\end{tabular}

Symbol Key: $\sqrt{ }$ Issue Addressed $\quad \varnothing$ Issue Not Addressed $\quad \uparrow$ Issue Addressed with Strong Language

$\downarrow$ Issue Addressed with Weak Language.

${ }^{1}$ See Table 2.

Note: To preserve confidentiality, names of schools and community partners are not provided in the tables. They are referred to as Agreement 1, Agreement 2, Agreement 3, and so forth. Permissions to reproduce some of the content presented in the tables were obtained from ChangeLab Solutions and the Los Angeles County Department of Public Health (Chronic Disease and Injury Prevention). The project was in part supported by the RWJF Public Health Law Research program.

As an initial matter, we acknowledge that not all shared use partnerships are memorialized in a written document. Oftentimes, the sharing of facilities occurs informally because of historical precedent, or perhaps as a result of a "handshake agreement” or simply because it's easier than formalizing existing practice. Formal, written shared use agreements are not appropriate in all contexts, but documenting an arrangement has its benefits. For example, the process of negotiating and signing an agreement allows the parties to share expectations and concerns, address those concerns, and ensure that everyone understands and agrees to the terms of the relationship. A written agreement is also more likely to outlast transitions of key staff or changes in budgetary priorities.

Los Angeles County communities have embraced written agreements, and as Tables 1 to 3 illustrate, they have found several ways to formalize shared use partnerships. From a purely legal perspective, the strongest agreements contain clear and robust language delineating roles and responsibilities, assigning potential liability, outlining a dispute resolution process, and specifying potential remedies in case of a 
breach of contract. They also contain provisions that address the potential conflicts and other issues likely to arise when two or more entities share property or facilities (e.g., priority of use, parking, access and security, maintenance, property/facility rules and regulations, insurance, cost allocation, etc.) (ChangeLab Solutions 2009; Zimmerman, Kramer, and Trowbridge 2013). These types of provisions undoubtedly help partners understand their respective rights and obligations, which is an essential component of any successful legal relationship.

However, from a public health legal perspective, we extended our analysis beyond standard contractual terms, and considered language that addresses or could address health outcomes, the broader impacts on the community, long-term sustainability, evaluation, interdisciplinary collaboration, and equity. Accordingly, our public health law analysis suggests that the best agreements include not only the aforementioned legal provisions, but also a 'health, equity, and sustainability lens' that gets at these larger policy goals. For example, one agreement in this study required a partner to provide ongoing technical assistance to "ensure sustainability of the program." Two agreements established collaborative working committees to discuss programming, scheduling, and operational and maintenance responsibilities. And another committed a partner to use its "best efforts" to provide scholarships to students who lack economic resources so that everyone, regardless of income, can participate in the scheduled activities. It is these types of provisions - and others that explicitly address health outcomes, equity, and sustainability, or outline tangible commitments to making the arrangement a success - that serve as models for school districts and community groups interested in pursuing shared use as a strategy for increasing physical activity in their resident population(s).

\section{Conclusions}

Los Angeles County has a variety of shared use agreements. Some schools and communities have entered into lengthy, detailed contracts; others have opted for simple permits or license agreements; and yet others have used memoranda of understanding. From a public health law perspective, some are clearly stronger than others, regardless of the legal mechanism used to document partners' intentions. However, the important lesson learned is that including language that describes each party's interest in community health, health equity, or sustainability represents a best practice that should be considered in every shared use agreement.

Results from this descriptive and legal examination of 20 existing shared use agreements in Los Angeles County provides important insights on how some of these agreements were constructed, and could help inform other jurisdictions' efforts to utilize shared use agreements for physical activity promotion and obesity prevention.

\section{Acknowledgments}

The authors thank staff at ChangeLab Solutions and the Los Angeles County Department of Public Health, Division of Chronic Disease and Injury Prevention for their technical assistance and support of this paper. The project was supported in part by the Robert Wood Johnson Foundation's Public Health Law Research program through Grant No. 70512. In addition to Mr. Winig and Dr. Kuo, the Framework for Shared Use Workgroup membership included (in alphabetical order): Ricardo Basurto-Dávila, Ph.D., M.S.; Lindsey Burbage, M.P.H.; Lauren Dunning, J.D., M.P.H.; Nancy J. Frank, M.P.H.; Eloisa Gonzalez, M.D., M.P.H.; Robert Oglivie, Ph.D.; Margaret Shih, M.D., Ph.D.; and Steven Teutsch,

\section{References}

Basurto-Dávila, Ricardo, Deena Pourshaban, and Duncan Mike Jackson. Impact of Shared Use Agreement Adoption on School District Expenditures in Los Angeles County. Los Angeles, CA: Los Angeles County Public Health Department; 2014. http://publichealth.lacounty.gov/PA/reports\%5CPHLR_JUA\%20Cost\%20Analysis_Final.pdf 
Carlton, Troy A., Michael A. Kanters, Jason N. Bocarro, Myron F. Floyd, Michael B. Edwards, Luis J. Suau. (2017). Shared use agreements and leisure time physical activity in North Carolina public schools. Preventive Medicine, 95, Suppl, S10-16.

Cox, Lindsey, Victoria Berends, James F. Sallis, Jessica Marie St. John, Betsy McNeil, Martin Gonzalez, and Peggy Agron. (2011). Engaging School Governance Leaders to Influence Physical Activity Policies. Journal of Physical Activity and Health, 8, Suppl 1, S40-8.

DeFosset, Amelia R., Lauren N. Gase, Eloisa Gonzalez, and Tony Kuo. (2016). Access to and Use of Schools for Physical Activity Among Adults in Los Angeles County. Health Promotion Practice, 17, no. 3, 416-28.

Eat Smart, Move More North Carolina. Move More: A Toolkit for Promoting Open Use of School Property in North Carolina. Raleigh, NC; 2016.

Eat Smart, Move More South Carolina. Breaking Physical Activity Barriers Through Open Community Use: Your Playbook. Columbia, SC: South Carolina Department of Health and Environmental Control; 2015.

Lafleur, Mariah, Eloisa Gonzalez, Liz Schwarte, Rajni Banthia, Tony Kuo, Joanie Verderber, and Paul Simon. (2013). Increasing Physical Activity in Under-Resourced Communities Through SchoolBased, Joint-Use Agreements, Los Angeles County, 2010-2012. Preventing Chronic Disease, 10, E89.

Model Joint Use Agreement Resources. (2009). ChangeLab Solutions website. http://changelabsolutions.org/publications/model-JUAs-national. Accessed July 11, 2017.

National Policy \& Legal Analysis Network to Prevent Childhood Obesity (NPLAN), ChangeLab Solutions, and KaBOOM! Eds. Manel Kappagoda and Robert S. Ogilvie. (2012). Playing Smart: Maximizing the Potential of School and Community Property Through Joint Use Agreements. Oakland (CA): ChangeLab Solutions. http://changelabsolutions.org/sites/default/files/Playing_SmartNational_Joint_Use_Toolkit_Updated_20120517_0.pdf.

Spengler, John O., Daniel P. Connaughton, and Jason E. Maddock. (2011). Liability Concerns and Shared Use of School Recreational Facilities in Underserved Communities. American Journal of Preventive Medicine, 41, no. 4, 415-20.

Vincent, Jeffrey M. (2014). Joint Use of Public Schools: A Framework for Promoting Healthy Communities. Journal of Planning Education and Research, 34, no. 2, 153-68.

Young, Deborah R., John O. Spengler, Natasha Frost, Kelly R. Evenson, Jeffrey M. Vincent, and Laurie Whitsel. (2014). Promoting Physical Activity Through the Shared Use of School Recreational Spaces: A Policy Statement from the American Heart Association. American Journal of Public Health, 104, no. 9, 1583-8.

Zimmerman, Sara, Karen Kramer, and Matthew J. Trowbridge. (2013). Overcoming Legal Liability Concerns for School-Based Physical Activity Promotion. American Journal of Public Health, 103, no. 11, $1962-7$.

Author Information

Tony Kuo, M.D., M.S.H.S.

Division of Chronic Disease and Injury Prevention

Los Angeles County Department of Public Health

3530 Wilshire Blvd, $8^{\text {th }}$ Floor

Los Angeles, CA 90010

Tel: (213) 351-7825; Fax: 213-351-2713

Email: tkuo@ph.lacounty.gov

* corresponding author 